\title{
Proteinuria predicts postcardiotomy acute kidney injury in patients with preserved glomerular filtration rate
}

\author{
Szu-Yuan Li, MD, ${ }^{\mathrm{a}, \mathrm{d}}$ Chiao-Lin Chuang, MD, ${ }^{\mathrm{b}, \mathrm{d}}$ Wu-Chang Yang, MD, ${ }^{\mathrm{a}}$ and Shing-Jong Lin, MD, PhD ${ }^{\mathrm{c}, \mathrm{d}}$
}

Objective: Acute kidney injury is a common and serious problem after cardiac surgery. Postoperative acute kidney injury is independently associated with in-hospital mortality and long-term morbidity, even after adjustment for comorbid diseases. Chronic kidney disease has been recognized as a strong risk factor of acute kidney injury after cardiac surgery. The association between proteinuria and postcardiotomy acute kidney injury in patients with preserved glomerular filtration rate remains uncertain.

\begin{abstract}
Methods: Patients with an estimated glomerular filtration rate greater than $60 \mathrm{~mL} / \mathrm{min} / 1.73 \mathrm{~m}^{2}$ who underwent cardiac surgery between January 2003 and December 2007 in a tertiary medical center were retrospectively analyzed. Dipstick urinalysis was performed before surgery. Proteinuria was categorized into negative, trace, $1+, 2+$, or $3+$. Postoperative acute kidney injury was defined by the Acute Kidney Injury Network criteria. Multinomial logistic regression was used to clarify whether proteinuria is an independent risk factor of postoperative acute kidney injury.
\end{abstract}

Results: A total of 1246 patients were included in this study, with a mean estimated glomerular filtration rate of $80 \pm 13 \mathrm{~mL} / \mathrm{min} / 1.73 \mathrm{~m}^{2}$. Proteinuria was present in 290 patients $(23.4 \%)$. Postoperative acute kidney injury developed in 434 patients $(34.8 \%)$, and 36 patients $(2.9 \%)$ required renal replacement therapy. Proteinuria was independently associated with all stages of postcardiotomy acute kidney injury and dialysis-requiring acute kidney injury. The crude risk of acute kidney injury was greater in patients with a higher grade of proteinuria. In subgroup analysis for gender, diabetes, and surgical type, preoperative proteinuria remains a strong risk factor of acute kidney injury after cardiac surgery.

Conclusions: Urine analysis is usually neglected before cardiac surgery despite the fact that proteinuria is the earliest manifestation of kidney dysfunction. In the current study, we show that urine protein is strongly and independently associated with postoperative acute kidney injury in subjects with preserved estimated glomerular filtration rate. These data suggest that such a relatively simple and clinically easy to use tool as a urinary dipstick may be useful to identify patients at high risk of acute kidney injury before cardiac surgery. (J Thorac Cardiovasc Surg 2015;149:894-9)

See related commentary on pages $900-1$.

Acute kidney injury (AKI) is a common and serious complication after cardiac surgery. It is independently associated with not only short-term but also long-term adverse outcomes. $^{1-4}$ Emerging evidences have suggested that

From the Divisions of Nephrology and General Medicine, ${ }^{\mathrm{b}}$ Departments of Medicine, and Medical Research, ${ }^{\mathrm{c}}$ Taipei Veterans General Hospital, Taipei, Taiwan; and Institution of Clinical Medicine, ${ }^{\mathrm{d}}$ National Yang Ming University, Taipei, Taiwan.

This work was supported by Grants V103B-005 and V102E2-002 from Taipei Veterans General Hospital and NSC 101-2314-B-075-038 and NSC 102-2633-B075-001 from National Science Council Taiwan.

Disclosures: Authors have nothing to disclose with regard to commercial support.

S.-Y.L. and C.-L.C. contributed equally to this work.

Received for publication June 3, 2014; revisions received Sept 3, 2014; accepted for publication Oct 6, 2014; available ahead of print Nov 26, 2014.

Address for reprints: Chiao-Lin Chuang, MD, Division of General Medicine, Department of Medicine, Taipei Veterans General Hospital, No 201, Sec 2, Shih-Pai Rd, Taipei 112, Taiwan (E-mail: clchuang @ vghtpe.gov.tw).

$0022-5223 / \$ 36.00$

Copyright ( 2015 by The American Association for Thoracic Surgery

http://dx.doi.org/10.1016/j.jtcvs.2014.10.054 even small changes in serum creatinine levels after cardiac surgery are associated with significant effects on mortality. ${ }^{5-7}$ Therefore, identification of the high-risk patients followed with appropriate intervention plays a critical role in improving the clinical outcome of cardiac surgery. Preoperative renal dysfunction usually is the most important determinant of postoperative AKI, and serum creatinine is routinely measured as a marker of renal function. ${ }^{8,9}$ Although clinicians have long recognized proteinuria to be the earliest manifestation of kidney dysfunction, the prognostic significance of the presence and severity of proteinuria was hindered among patients with preserved glomerular filtration rate (GFR).

Community-based studies by James and colleagues ${ }^{10}$ and Grams and colleagues ${ }^{11}$ have shown that the presence of proteinuria is associated with an increased risk of subsequent AKI among patients with estimated glomerular filtration rate (eGFR) greater than $60 \mathrm{~mL} / \mathrm{min} / 1.73 \mathrm{~m}^{2}$. Both studies confirmed the prognostic value of proteinuria in the development of AKI despite normal serum creatinine. In addition, the association among proteinuria, adverse renal outcomes, and mortality in patients undergoing 

Abbreviations and Acronyms
$\mathrm{AKI}=$ acute kidney injury
AKIN $=$ Acute Kidney Injury Network
eGFR $=$ estimated glomerular filtration rate
$\mathrm{GFR}=$ glomerular filtration rate
IABP $=$ intra-aortic balloon pump
RRT $=$ renal replacement therapy

percutaneous coronary intervention ${ }^{12}$ and coronary artery bypass surgery ${ }^{13}$ has been reported. However, the prognostic significance of proteinuria on postcardiotomy AKI in patients with preserved eGFR has remained unknown. The current study assesses the impact of preoperative proteinuria on AKI after cardiac surgery in subjects with eGFR greater than $60 \mathrm{~mL} / \mathrm{min} / 1.73 \mathrm{~m}^{2}$.

\section{MATERIALS AND METHODS}

\section{Study Subjects}

This is a retrospective cohort study approved by the institutional review board. All consecutive adult patients who underwent cardiac surgery with cardiopulmonary bypass from January 1, 2003, to December 31, 2008, at Taipei Veterans General Hospital entered this study. Patients who were on maintenance dialysis or who underwent heart transplantation were ineligible for this study. Patients with preoperative eGFR less than $60 \mathrm{~mL} / \mathrm{min} / 1.73 \mathrm{~m}^{2}$ were also excluded (Figure 1).

\section{Data Collection}

Demographic and clinical data, such as age, gender, body weight, body mass index, diabetes, and left ventricular ejection fraction, were obtained from medical records. Hemoglobin, serum creatinine, and albumin were measured before surgery. Duration of cardiopulmonary bypass, preoperative treatment of intra-aortic balloon pump (IABP), and types of operation were obtained from surgical records.

\section{Baseline Urine Protein and Acute Kidney Injury}

A urine sample was collected during a 3-day period before surgery. The presence of proteinuria was determined using an automatic dipstick analyzer (CLINITEK Atlas; Siemens Healthcare Diagnostics, Eschborn, Germany). The degree of proteinuria was semiquantified as negative, trace (protein $15-30 \mathrm{mg} / \mathrm{dL}), 1+(30-100 \mathrm{mg} / \mathrm{dL}), 2+(100-300 \mathrm{mg} / \mathrm{dL})$, or $3+(>300 \mathrm{mg} / \mathrm{dL})$.

Preoperative eGFR was calculated by the Cockcroft-Gault formula as follows for men: $(140$ - age) $\times$ (body weight in kilograms)/ ( $72 \times$ serum creatinine). In women, the value was multiplied by $0.85 .{ }^{14}$ Blood chemistries were checked with a 24-hour interval after operation

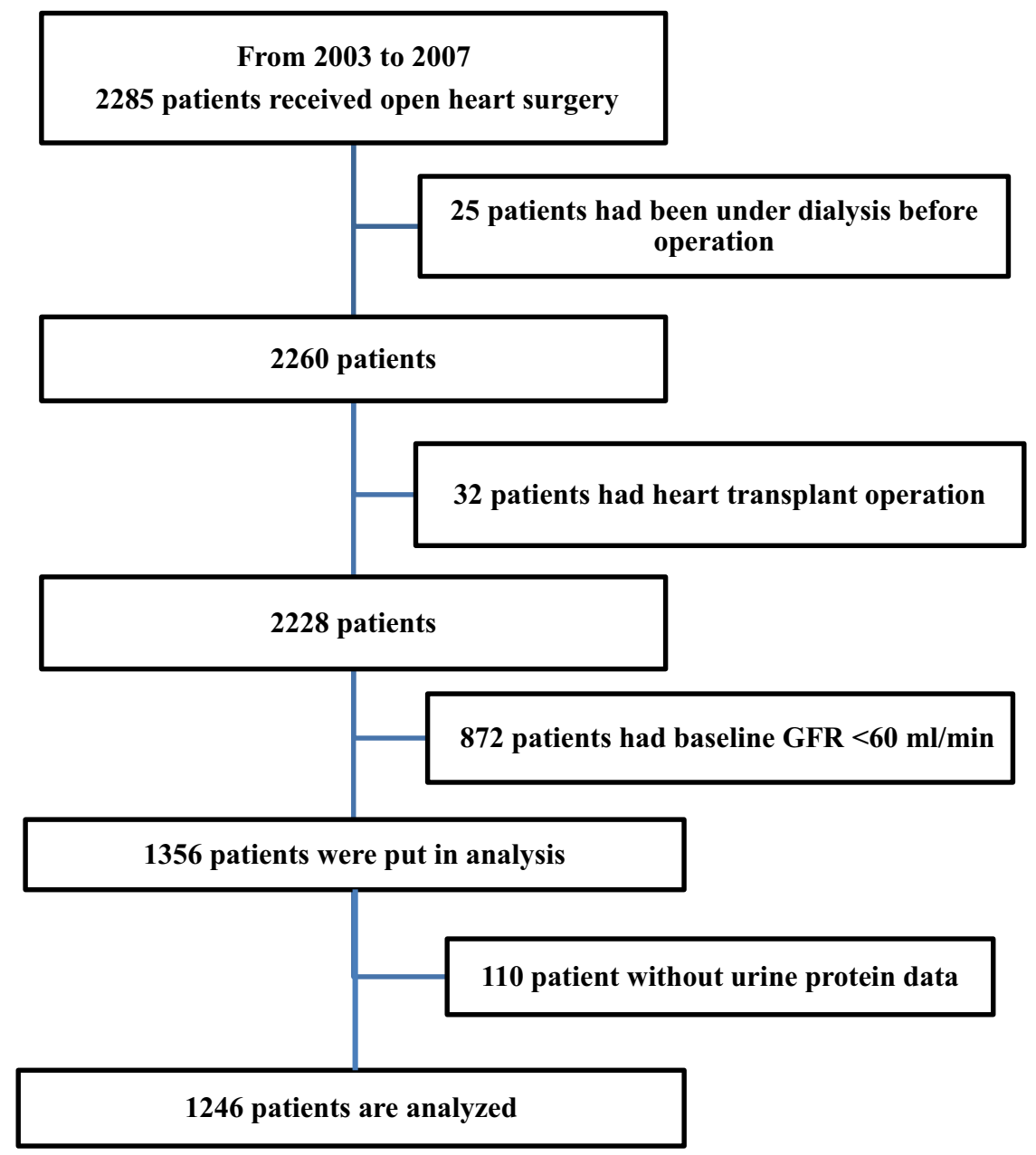

FIGURE 1. Patient selection flow. GFR, Glomerular filtration rate. 
TABLE 1. Baseline characteristics of study patients

\begin{tabular}{lc}
\hline \multicolumn{1}{c}{ Variable } & $(\mathbf{n}=\mathbf{1 2 4 6})$ \\
\hline Demographic data & \\
Male gender & $963(77.3 \%)$ \\
Age $(\mathrm{y})$ & $61.5 \pm 15.5$ \\
Body mass index $\left(\mathrm{kg} / \mathrm{m}^{2}\right)$ & $24.3 \pm 3.6$ \\
Diabetes & $329(26.5 \%)$ \\
LV ejection fraction & $51.0 \% \pm 13.5 \%$ \\
Surgery type & \\
CABG & $705(56.6 \%)$ \\
Valve & $476(38.2 \%)$ \\
CABG + valve & $73(5.8 \%)$ \\
Others & $193(15.5 \%)$ \\
Perioperative parameter & \\
Urgent surgery & $177(14.2 \%)$ \\
Preoperative IABP & $88(7.1 \%)$ \\
Bypass time (min) & $153 \pm 71$ \\
Biochemical data & \\
Hemoglobin $(\mathrm{g} / \mathrm{dL})$ & $11.2 \pm 1.8$ \\
Albumin $(\mathrm{g} / \mathrm{dL})$ & $3.6 \pm 0.7$ \\
Creatinine (mg/dL) & $0.9 \pm 0.2$ \\
eGFR (mL/min/1.72 $\left.\mathrm{m}^{2}\right)$ & $80 \pm 13$ \\
\hline CABG Con
\end{tabular}

$C A B G$, Coronary artery bypass grafting; $e G F R$, estimated glomerular filtration rate; $I A B P$, intra-aortic balloon pump; $L V$, left ventricle.

AKI was defined and categorized into 3 stages by the Acute Kidney Injury Network (AKIN) criteria. ${ }^{15}$

\section{Indication for Renal Replacement Therapy}

The indications for renal replacement therapy (RRT) were as follows: oliguria (urine output $<240 \mathrm{~mL} / 12$ hours) despite fluid resuscitation and intravenous diuretic treatment, severe hyperkalemia greater than $6.5 \mathrm{mmol} / \mathrm{L}$, severe acidosis $(\mathrm{pH}<7.2$ ), or pulmonary edema. The decision to initiate or terminate RRT was determined by the consulting nephrologists.

\section{Statistical Analysis}

Normally distributed continuous data were expressed as mean \pm standard deviation. Statistical analysis was performed with SPSS 15.0 software (IBM, Chicago, Ill). To identify risk factors for different stages of postoperative AKI, a multinominal logistic regression model was performed. To identify independent risk factors for dialysis-requiring AKI, a binominal multivariate logistic stepwise regression model was used. Risk factors with a $P$ value less than .1 in univariate analysis were entered into the multivariate analysis, and a logistic assumption was tested for all continuous variables in this model. All probabilities were 2 tailed.

\section{RESULTS}

\section{Basic Characteristics of Study Population}

During the 6-year study period, 2285 consecutive patients underwent cardiac surgery with cardiopulmonary bypass at Taipei Veterans General Hospital. After excluding patients receiving maintenance dialysis and heart transplantation, 1246 patients with baseline eGFR greater than 60 $\mathrm{mL} / \mathrm{min} / 1.73 \mathrm{~m}^{2}$ were included in the study. The clinical characteristics of the study cohort are shown in Table 1. Patients' mean age was $61.5 \pm 15.5$ years and mean baseline eGFR was $80 \pm 13 \mathrm{~mL} / \mathrm{min} / 1.73 \mathrm{~m}^{2}$. The distribution

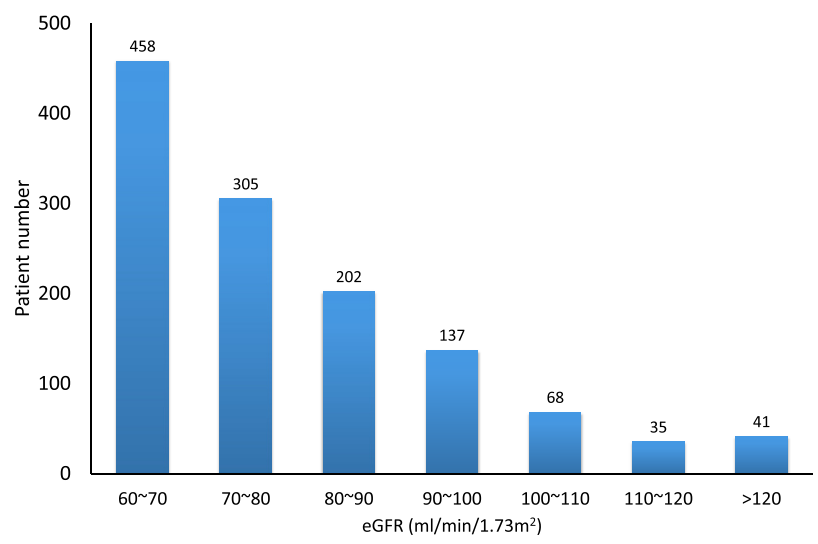

FIGURE 2. Distribution plot of eGFR in study population. eGFR, Estimated glomerular filtration rate.

plot of eGFR is shown in Figure 2; 26.5\% $(\mathrm{n}=330)$ of the subjects were diabetic.

\section{Acute Kidney Injury Incidence Stratified by Category of Proteinuria}

A total of $23.4 \%$ of patients $(n=290)$ had preoperative proteinuria. The overall incidence rate of AKI was $34.8 \%$ $(\mathrm{n}=434)$, including $26.2 \%(\mathrm{n}=326)$ in AKIN stage 1 , $3.6 \%(\mathrm{n}=45)$ in AKIN stage 2, and $5 \%(\mathrm{n}=63)$ in AKIN stage 3 . Only 36 patients $(2.9 \%)$ required RRT after surgery. The crude risk of AKI was greater in patients with proteinuria. When stratified into groups of dipstick negative, trace, $1+, 2+$, or $3+$, there was a stepwise increase in incidence of postcardiotomy AKI with greater levels of proteinuria (Table 2).

\section{Multinomial Logistic Regression Model for Postoperative Acute Kidney Injury}

Independent risk factors for all stages of postoperative AKI were high body mass index, low serum albumin, longer bypass time, urgent surgery, requirement of preoperative IABP or extracorporeal membranous oxygenation, and presence of proteinuria. Diabetes was an independent risk factor for developing AKIN stage 1 but not for higher stages. On the other hand, lower eGFR was a risk factor

TABLE 2. Cross table between preoperative proteinuria and postcardiotomy acute kidney injury

\begin{tabular}{llrrrrrr}
\hline & & \multicolumn{5}{c}{ Category of proteinuria } & \\
\cline { 3 - 6 } & & Negative & Trace & $\mathbf{1}+$ & $\mathbf{2 +}$ & $\mathbf{3}+$ & Total \\
\hline AKIN & No & 587 & 81 & 97 & 43 & 4 & 812 \\
& Stage 1 & 213 & 25 & 53 & 22 & 13 & 326 \\
& Stage 2 & 17 & 5 & 11 & 8 & 4 & 45 \\
& Stage 3 & 22 & 6 & 22 & 8 & 5 & 63 \\
Total & & 839 & 117 & 183 & 81 & 26 & 1246 \\
\hline
\end{tabular}

Pearson chi-square $P<.0001$, likelihood ratio $P<.0001$. AKIN, Acute Kidney Injury Network. 
for developing AKIN stage 3 but not for lower stages. The incremental possibility of developing AKI paralleled with incremental severity of proteinuria (Table 3 ).

\section{Multivariate Logistic Regression Model for Acute Kidney Injury Requiring Renal Replacement Therapy}

Independent risk factors of dialysis-requiring AKI were urgent surgery, requirement of preoperative IABP, lower eGFR, and presence of proteinuria. The incremental possibility of developing RRT-requiring AKI also paralleled with incremental severity of proteinuria (Table 4).

\section{Subgroup Analysis}

To validate the risk of proteinuria for postoperative AKI in various patient populations, we performed subgroup

TABLE 3. Risk factors for postcardiotomy acute kidney injury

\begin{tabular}{|c|c|c|c|c|}
\hline AKIN stage & OR & $\begin{array}{c}P \\
\text { value }\end{array}$ & $\begin{array}{c}\text { Lower } \\
95 \% \text { CI }\end{array}$ & $\begin{array}{c}\text { Upper } \\
95 \% \text { CI }\end{array}$ \\
\hline \multicolumn{5}{|l|}{ AKIN stage $1(\mathrm{n}=326)$} \\
\hline Body mass index & 1.068 & .001 & 1.028 & 1.109 \\
\hline LV ejection fraction $(\%)$ & 1.120 & .790 & 0.487 & 2.576 \\
\hline Hemoglobin (mg/dL) & 0.937 & .087 & 0.870 & 1.009 \\
\hline Albumin (g/L) & 0.698 & .000 & 0.575 & 0.846 \\
\hline Bypass time (min) & 1.006 & .000 & 1.004 & 1.008 \\
\hline Age (y) & 1.001 & .868 & 0.988 & 1.015 \\
\hline eGFR (mL/min) & 0.993 & .079 & 0.985 & 1.001 \\
\hline Male gender & 1.535 & .005 & 1.136 & 2.074 \\
\hline Diabetes & 1.319 & .041 & 1.011 & 1.721 \\
\hline Urgent surgery & 2.512 & .000 & 1.650 & 3.822 \\
\hline IABP & 2.041 & .008 & 1.202 & 3.465 \\
\hline ECMO & 1.433 & .447 & 0.566 & 3.629 \\
\hline \multicolumn{5}{|c|}{ Proteinuria (negative proteinuria as reference) } \\
\hline Proteinuria trace & 3.408 & .001 & 1.667 & 6.967 \\
\hline Proteinuria $1+$ & 3.489 & .000 & 1.770 & 6.878 \\
\hline Proteinuria $2+$ & 5.408 & .000 & 2.652 & 11.029 \\
\hline Proteinuria $3+$ & 3.850 & .000 & 2.044 & 7.251 \\
\hline \multicolumn{5}{|l|}{ AKIN stage $2(n=45)$} \\
\hline Body mass index & 0.962 & .474 & 0.864 & 1.070 \\
\hline LV ejection fraction $(\%)$ & 0.881 & .910 & 0.096 & 8.048 \\
\hline Hemoglobin (mg/dL) & 0.962 & 698 & 0.792 & 1.169 \\
\hline Albumin $(\mathrm{g} / \mathrm{L})$ & 0.508 & .010 & 0.304 & 0.849 \\
\hline Bypass time (min) & 1.007 & .003 & 1.002 & 1.011 \\
\hline Age (y) & 1.058 & .006 & 1.016 & 1.101 \\
\hline eGFR (mL/min) & 1.019 & .054 & 1.000 & 1.040 \\
\hline Male sex & 1.005 & .990 & 0.450 & 2.245 \\
\hline $\mathrm{DM}$ & 1.461 & .285 & 0.729 & 2.926 \\
\hline Urgent surgery & 2.294 & .090 & 0.878 & 5.996 \\
\hline IABP & 4.845 & .001 & 1.951 & 12.029 \\
\hline ECMO & 5.866 & .006 & 1.642 & 20.963 \\
\hline \multicolumn{5}{|c|}{ Proteinuria (negative proteinuria as reference) } \\
\hline Proteinuria trace & 2.858 & .110 & 0.788 & 10.370 \\
\hline Proteinuria $1+$ & 11.437 & .001 & 2.710 & 48.275 \\
\hline Proteinuria $2+$ & 4.926 & .018 & 1.318 & 18.403 \\
\hline Proteinuria $3+$ & 12.882 & .000 & 3.753 & 44.223 \\
\hline
\end{tabular}

TABLE 3. Continued

\begin{tabular}{lcccr}
\hline \multicolumn{1}{c}{ AKIN stage } & OR & $\begin{array}{c}\boldsymbol{P} \\
\text { value }\end{array}$ & $\begin{array}{c}\text { Lower } \\
\mathbf{9 5} \% \mathbf{C I}\end{array}$ & $\begin{array}{c}\text { Upper } \\
\mathbf{9 5} \% \mathbf{C I}\end{array}$ \\
\hline AKIN stage 3 (n=63) & & & & \\
Body mass index & 1.095 & .008 & 1.024 & 1.172 \\
LV ejection fraction (\%) & 1.053 & .942 & 0.261 & 4.242 \\
Hemoglobin (mg/dL) & 0.917 & .184 & 0.808 & 1.042 \\
Albumin (g/L) & 0.600 & .003 & 0.427 & 0.841 \\
Bypass time (min) & 1.009 & .000 & 1.005 & 1.012 \\
Age (y) & 0.995 & .686 & 0.971 & 1.020 \\
eGFR (mL/min) & 0.946 & .000 & 0.931 & 0.961 \\
Male sex & 0.949 & .837 & 0.579 & 1.556 \\
Diabetes & 1.525 & .084 & 0.944 & 2.462 \\
Urgent surgery & 4.719 & .000 & 2.573 & 8.655 \\
IABP & 4.178 & .000 & 2.147 & 8.129 \\
ECMO & 23.757 & .000 & 9.545 & 59.131 \\
Proteinuria (negative proteinuria as reference) & & \\
$\quad$ Proteinuria trace & 3.189 & .006 & 1.402 & 7.252 \\
Proteinuria 1+ & 5.044 & .000 & 2.216 & 11.485 \\
Proteinuria 2+ & 10.558 & .000 & 3.891 & 28.651 \\
Proteinuria 3+ & 13.733 & .000 & 6.107 & 30.883
\end{tabular}

Model fitting $P<.0001$, goodness for fit $P=.006$, likelihood ratio test for proteinuria $P<.0001$. AKIN, Acute Kidney Injury Network; $C I$, confidence interval; $D M$, diabetes mellitus; $E C M O$, extracorporeal membranous oxygenation; $e G F R$, estimated glomerular filtration rate; $I A B P$, intra-aortic balloon pump; $L V$, left ventricular; $O R$, odds ratio.

analysis for gender, diabetes, and surgical type. Proteinuria (urine dipstick greater than trace) remained a risk factor for all stages of postoperative AKI in all prespecified subgroups (Figure 3).

\section{DISCUSSION}

In previous investigations, ${ }^{10-13}$ an equal importance of both eGFR and proteinuria in the assessment of AKI has been found. Our results extended this association across the full range of proteinuria and to all cardiac surgery, even in patients with an eGFR greater than $60 \mathrm{~mL} / \mathrm{min} / 1.73 \mathrm{~m}^{2}$. This was the first study to quantify the graded relationship between proteinuria and risk of postcardiotomy AKI among patients with preserved eGFR. It showed a graded increase in the hazards of AKI along the worsening proteinuria categories, measured by using standard urinary dipstick, in patients undergoing cardiac surgery. This association was essentially unaltered despite extensive statistical adjustment for gender, traditional cardiac risk factors, diabetes mellitus, or modality of surgery.

The mechanisms of postcardiotomy AKI are multifactorial. Intraoperative hypotension, ischemia-reperfusion injury of cardiopulmonary bypass, oxidative stress, activation of inflammatory cytokines, and postoperative low cardiac output have been speculated as the causes. ${ }^{14-}$ ${ }^{19}$ The final event is tubular damage and GFR decline. Accordingly, it is well accepted that patients with lower GFR are more vulnerable to these insults, and consequently kidney damage develops after the operation. 
TABLE 4. Risk factors for dialysis-requiring acute kidney injury after cardiac surgery $(\mathbf{n}=\mathbf{3 6})$

\begin{tabular}{|c|c|c|c|c|c|c|c|c|}
\hline \multirow[b]{2}{*}{ Parameters } & \multicolumn{4}{|c|}{ Unadjusted } & \multicolumn{4}{|c|}{ Multivariate adjusted } \\
\hline & OR & $95 \%$ CI & $95 \% \mathrm{CI}$ & $P$ value & OR & $95 \% \mathrm{CI}$ & $\mathbf{9 5} \% \mathrm{CI}$ & $P$ value \\
\hline Age (per 10 y) & 1.19 & 0.91 & 1.57 & .203 & & & & \\
\hline Body mass index & 0.99 & 0.95 & 1.04 & .770 & & & & \\
\hline Male gender & 1.85 & 0.71 & 4.80 & .207 & & & & \\
\hline Diabetes & 1.30 & 0.59 & 2.50 & .590 & & & & \\
\hline Urgent surgery & 3.25 & 1.71 & 6.16 & $<.001$ & 3.14 & 1.70 & 5.79 & $<.001$ \\
\hline LV ejection fraction (per 10\%) & 0.56 & 0.12 & 2.68 & .470 & & & & \\
\hline Preoperative IABP & 2.73 & 1.38 & 5.37 & .004 & 3.15 & 1.63 & 6.07 & .001 \\
\hline Bypass time (per $10 \mathrm{~min}$ ) & 1.00 & 1.00 & 1.01 & .131 & & & & \\
\hline Hemoglobin (mg/dL) & 0.92 & 0.79 & 1.06 & .256 & & & & \\
\hline Albumin (mg/dL) & 0.71 & 0.48 & 1.04 & .081 & & & & \\
\hline $\mathrm{eGFR}\left(\mathrm{mL} / \mathrm{min} / 1.72 \mathrm{~m}^{2}\right)$ & 0.95 & 0.94 & 0.96 & .021 & & & & \\
\hline Urine protein by dipstick & & & & $<.001$ & & & & $<.001$ \\
\hline Negative & 1 & & & & 1 & & & \\
\hline Trace & 1.29 & 0.47 & 3.59 & .619 & 1.22 & 0.44 & 3.325 & .701 \\
\hline $1+$ & 2.82 & 1.33 & 5.99 & .007 & 3.31 & 1.60 & 6.83 & .001 \\
\hline $2+$ & 5.72 & 2.76 & 11.87 & $<.0001$ & 6.33 & 3.13 & 12.83 & $<.0001$ \\
\hline $3+$ & 9.57 & 4.49 & 20.42 & $<.0001$ & 11.22 & 5.40 & 23.30 & $<.0001$ \\
\hline
\end{tabular}

On the contrary, proteinuria reflects an altered glomerular filtration barrier integrity rather than an altered GFR. As the earliest manifestation of glomerular damage, proteinuria may be present in the setting of a normal GFR, such as diabetes, hypertension, and glomerular disease. Thus, the casual relationship between proteinuria and AKI needs to be explored. There are several possible explanations. At first, proteinuria is the earliest

\section{Stage 1 AKI}

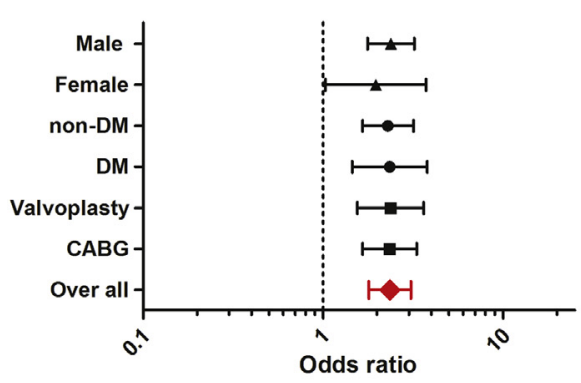

Stage 3 AKI

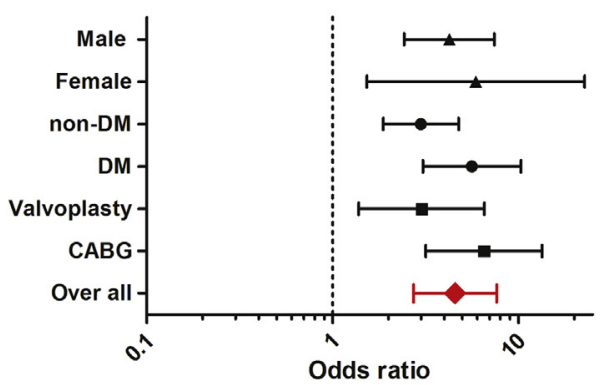

manifestation of glomerular damage; "damaged kidneys" have a higher possibility of further injury during operation. Another possible explanation is systemic endothelial cell injury. ${ }^{20-22}$ Because proteinuria is strongly accepted as a surrogate marker of endothelial dysfunction, proteinuria in patients undergoing cardiac surgery might reflect systemic endothelial dysfunction, making kidneys less able to tolerate hemodynamic changes during

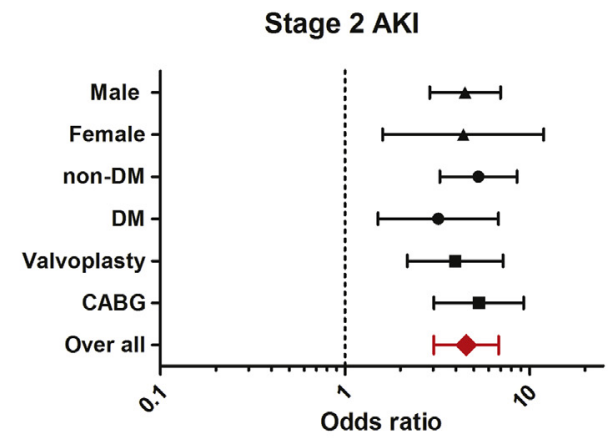

AKI required RRT

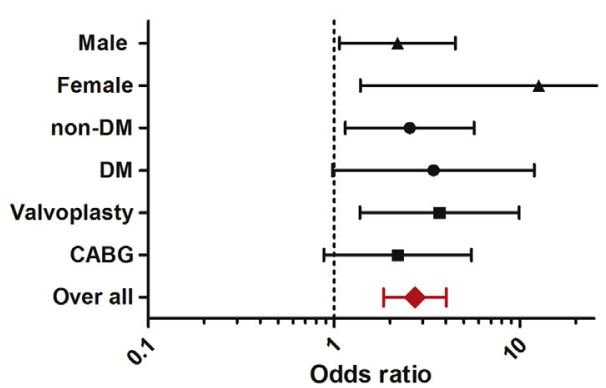

FIGURE 3. Subgroup analysis of proteinuria in postoperative AKI. $A K I$, Acute kidney injury; $C A B G$, coronary artery bypass grafting; $D M$, diabetes mellitus; $R R T$, renal replacement therapy. 
operation and eventually developing postoperative AKI. Regardless of the causes, proteinuric patients undergoing cardiac surgery may benefit from closer surveillance.

Previous epidemiologic studies consistently showed that proteinuria predicted mortality in populations with and without diabetes or cardiovascular disease. ${ }^{23,24}$ Likewise, we showed that the association of proteinuria with AKI was similar between diabetic and nondiabetic subjects, despite diabetes being well known as a strong independent risk factor for AKI. It is plausible that the potential impact of diabetes mellitus might be due to the coexisting proteinuria.

\section{Study Limitations}

At first, this study was conducted at a single center, which may limit the use of its results to other centers. However, the mortality rate and incidence of AKI found in our population compared well with those from prior studies. ${ }^{3,5,13}$ Second, the standard urinary dipstick, an inexpensive and simple tool to identify the presence of proteinuria, is also a relatively insensitive marker of urinary protein excretion. Whether microalbuminuria may represent a more sensitive test to identify persons at increased risk of AKI after cardiac surgery requires further evaluation in future studies. Third, to focus the prognostic impact of "postcardiotomy acute kidney injury" by AKIN criteria, AKI occurring 48 hours after surgery was not entered in the analysis, although this might increase the predictive power of mortality. Fourth, as is true in retrospective and observational studies, several potential risk factors for AKI were not investigated, such as intraoperative hypotension and degree of hemodilution.

\section{CONCLUSIONS}

There was a graded association between the severity of preoperative proteinuria and the risk of AKI after cardiac surgery. The finding that even a small amount of proteinuria from a simple urine dipstick may serve as a "low eGFR equivalent" to identify a hitherto neglected subset of atrisk individuals has therapeutic implications. These results also underscore that the current staging system of chronic kidney disease based primarily on the eGFR without fully incorporating the severity of concomitant proteinuria can be improved. It is important that future studies address whether medications that decrease proteinuria might be associated with a decrease in mortality in patients undergoing cardiac surgery or whether proteinuria is simply a marker of early kidney disease or endothelial dysfunction.

\section{References}

1. Li SY, Chen JY, Yang WC, Chuang CL. Acute kidney injury network classification predicts in-hospital and long-term mortality in patients undergoing elective coronary artery bypass grafting surgery. Eur J Cardiothorac Surg. 2011; 39:323-8.
2. Brown JR, Cochran RP, Dacey LJ, Ross CS, Kunzelman KS, Dunton RF, et al. Perioperative increases in serum creatinine are predictive of increased 90-day mortality after coronary artery bypass graft surgery. Circulation. 2006;114:I409-13.

3. Loef BG, Epema AH, Smilde TD, Henning RH, Ebels T, Navis G, et al. Immediate postoperative renal function deterioration in cardiac surgical patients predicts in-hospital mortality and long-term survival. J Am Soc Nephrol. 2005; 16:195-200

4. Mangano CM, Diamondstone LS, Ramsay JG, Aggarwal A, Herskowitz A, Mangano DT, et al. Renal dysfunction after myocardial revascularization: risk factors, adverse outcomes, and hospital resource utilization. The Multicenter Study of Perioperative Ischemia Research Group. Ann Intern Med. 1998;128:194-203.

5. Lassnigg A, Schmidlin D, Mouhieddine M, Bachmann LM, Druml W, Bauer P, et al. Minimal changes of serum creatinine predict prognosis in patients after cardiothoracic surgery: a prospective cohort study. J Am Soc Nephrol. 2004;15:1597-605.

6. Thakar CV, Worley S, Arrigain S, Yared JP, Paganini EP. Influence of renal dysfunction on mortality after cardiac surgery: modifying effect of preoperative renal function. Kidney Int. 2005;67:1112-9.

7. Miceli A, Bruno VD, Capoun R, Romero F, Angelini GD, Caputo M, et al. Occult renal dysfunction: a mortality and morbidity risk factor in coronary artery bypass grafting surgery. J Thorac Cardiovasc Surg. 2011;141:771-6.

8. Zakeri R, Freemantle N, Barnett V, Lipkin GW, Bonser RS, Graham TR, et al. Relation between mild renal dysfunction and outcomes after coronary artery bypass grafting. Circulation. 2005;112:I270-5.

9. Cooper WA, O'Brien SM, Thourani VH, Guyton RA, Bridges CR, Szczech LA, et al. Impact of renal dysfunction on outcomes of coronary artery bypass surgery: results from the Society of Thoracic Surgeons National Adult Cardiac Database. Circulation. 2006;113:1063-170.

10. James MT, Hemmelgarn BR, Wiebe N, Pannu N, Manns BJ, Klarenbach SW, et al. Glomerular filtration rate, proteinuria, and the incidence and consequences of acute kidney injury: a cohort study. Lancet. 2010;376:2096-103.

11. Grams ME, Astor BC, Bash LD, Matsushita K, Wang Y, Coresh J. Albuminuria and estimated glomerular filtration rate independently associate with acute kidney injury. J Am Soc Nephrol. 2010;21:1757-64.

12. Mercado N, Brugts JJ, Ix JH, Dixon SR, Gersh BJ, et al. Usefulness of proteinuria as a prognostic marker of mortality and cardiovascular events among patients undergoing percutaneous coronary intervention (data from the Evaluation of Oral Xemilofiban in Controlling Thrombotic Events [EXCITE] trial). Am J Cardiol. 2008;102:1151-5.

13. Huang TM, Wu VC, Young GH, Lin YF, Shiao CC, Wu PC, et al. Preoperative proteinuria predicts adverse renal outcomes after coronary artery bypass grafting. J Am Soc Nephrol. 2011;22:156-63.

14. Cockcroft DW, Gault MH. Prediction of creatinine clearance from serum creatinine. Nephron. 1976;16:31-41

15. Mehta RL, Kellum JA, Shah SV, Molitoris BA, Ronco C, Warnock DG, et al. Acute Kidney Injury Network: report of an initiative to improve outcomes in acute kidney injury. Crit Care. 2007;11:R31.

16. Rosner MH, Okusa MD. Acute kidney injury associated with cardiac surgery Clin J Am Soc Nephrol. 2006;1:19-32.

17. Bellomo R, Auriemma S, Fabbri A, D’Onofrio A, Katz N, McCullough PA, et al. The pathophysiology of cardiac surgery-associated acute kidney injury (CSA-AKI). Int J Artif Organs. 2008;31:166-78.

18. McCoy RN, Hill KE, Ayon MA, Stein JH, Burk RF. Oxidant stress following renal ischemia: changes in the glutathione redox ratio. Kidney Int. 1988;33:812-7.

19. Cremer J, Martin M, Redl H, Bahrami S, Abraham C, Graeter T, et al. Systemic inflammatory response syndrome after cardiac operations. Ann Thorac Surg. 1996;61:1714-20.

20. Stehouwer CD, Nauta JJ, Zeldenrust GC, Hackeng WH, Donker AJ, den Ottolander GJ. Urinary albumin excretion, cardiovascular disease, and endothelial dysfunction in non-insulin-dependent diabetes mellitus. Lancet. 1992;340:319-23.

21. Pedrinelli R, Giampietro O, Carmassi F, Melillo E, Dell'Omo G, Catapano G et al. Microalbuminuria and endothelial dysfunction in essential hypertension. Lancet. 1994;344:14-8.

22. Clausen P, Jensen JS, Jensen G, Borch-Johnsen K, Feldt-Rasmussen B. Elevated urinary albumin excretion is associated with impaired arterial dilatory capacity in clinically healthy subjects. Circulation. 2001;103:1869-74.

23. Gerstein HC, Mann JF, Yi Q, Zinman B, Dinneen SF, Hoogwerf B, et al. Albuminuria and risk of cardiovascular events, death, and heart failure in diabetic and nondiabetic individuals. JAMA. 2001;286:421-6.

24. Hillege HL, Fidler V, Diercks GF, van Gilst WH, de Zeeuw D, van Veldhuisen DJ, et al. Urinary albumin excretion predicts cardiovascular and noncardiovascular mortality in general population. Circulation. 2002;106:1777-82. 